\title{
Extinction and the U.S. Endangered Species Act
}

\author{
Noah Greenwald ${ }^{\text {Corresp., }}{ }^{1}$, Kieran F Suckling ${ }^{2}{ }^{,}$Brett Hartl $^{3}$, Loyal Mehrhoff $^{4}$ \\ ${ }^{1}$ Center for Biological Diversity, Portland, Oregon, United States \\ 2 Center for Biological Diversity, Tucson, Arizona, United States \\ ${ }^{3}$ Center for Biological Diversity, Washington DC, United States \\ ${ }^{4}$ Center for Biological Diversity, Honolulu, Hawaii, United States \\ Corresponding Author: Noah Greenwald \\ Email address: ngreenwald@biologicaldiversity.org
}

The United States Endangered Species Act is one of the strongest laws of any nation for preventing species extinction, but quantifying the Act's effectiveness has proven difficult. To provide one measure of effectiveness, we identified listed species that have gone extinct and used previously developed methods to update an estimate of the number of species extinctions prevented by the Act. To date, only four species have been confirmed extinct with another 22 possibly extinct following protection. Another 71 listed species are extinct or possibly extinct, but were last seen before protections were enacted, meaning the Act's protections never had the opportunity to save these species. In contrast, a total of 39 species have been fully recovered, including 23 in the last 10 years. We estimate the Endangered Species Act has prevented the extinction of roughly 291 species since passage in 1973, and has to date saved more than 99 percent of species under its protection. 
1 Extinction and the U.S. Endangered Species Act

2

3 Noah Greenwald ${ }^{1}$, Kieran F. Suckling ${ }^{2}$, Brett Hartl ${ }^{3}$, Loyal Mehrhoff ${ }^{4}$

4

$5{ }^{1}$ Center for Biological Diversity, Portland, Oregon, USA

$6{ }^{2}$ Center for Biological Diversity, Tucson, Arizona, USA

$7 \quad{ }^{3}$ Center for Biological Diversity, Washington DC, USA

$8{ }^{4}$ Center for Biological Diversity, Honolulu, Hawaii, USA

9

10 Corresponding Author:

11 Noah Greenwald ${ }^{1}$

12 PO Box 11374, Portland, OR 97211, USA

13 Email address: ngreenwald@biologicaldiversity.org

14

15

16

17

18

19

20

21

22

23

Peer] reviewing PDF | (2019:01:34008:1:0:NEW 9 Mar 2019) 


\section{Abstract:}

25 The United States Endangered Species Act is one of the strongest laws of any nation for

26 preventing species extinction, but quantifying the Act's effectiveness has proven difficult. To

27 provide one measure of effectiveness, we identified listed species that have gone extinct and used previously developed methods to update an estimate of the number of species extinctions prevented by the Act. To date, only five species have been confirmed extinct with another 22 possibly extinct following protection. Another 71 listed species are extinct or possibly extinct, but were last seen before protections were enacted, meaning the Act's protections never had the opportunity to save these species. In contrast, a total of 39 species have been fully recovered, including 23 in the last 10 years. We estimate the Endangered Species Act has prevented the extinction of roughly 291 species since passage in 1973, and has to date saved more than 99 percent of species under its protection. 


\section{Introduction}

48 Passed in 1973, the U.S. Endangered Species Act (ESA) includes strong protections for listed

49 threatened and endangered species and has helped stabilize and recover hundreds of listed

50 species, such as the bald eagle and gray whale (Taylor et al., 2006; Schwartz, 2008; Suckling et

51 al., 2016). In part because of its strong protections, the ESA has engendered substantial

52 opposition from industry lobby groups, who perceive the law as threatening their profits and

53 have been effective in generating opposition to species protections among members of the U.S.

54 Congress. One common refrain from opponents of the ESA in Congress and elsewhere is that

55 the law is a failure because only two percent of listed species have been fully recovered and

56 delisted (Hastings et. al., 2014).

57

58

The number of delistings, however, is a poor measure of the success of the ESA because most species have not been protected for sufficient time such that they would be expected to have recovered. Suckling et al. (2016), for example, found that on average listed birds had been protected just 36 years, but their federal recovery plans estimated an average of 63 years for recovery. Short of recovery, a number of studies have found the ESA is effectively stabilizing or improving the status of species, using both biennial status assessments produced by the U.S. Fish and Wildlife Service for Congress and abundance trends (Male \& Bean, 2005; Taylor et al., 2006; Gibbs \& Currie, 2012; Suckling et al., 2016).

In addition to recovering species, one of the primary purposes of the ESA is to prevent species extinction. Previous studies indicate the ESA has been successful in this regard (McMillan \& Wilcove, 1994; Scott et al., 2006). As of 2008, the ESA was estimated to have prevented the 
70

71

72

73

74

75

76

77

78

extinction of at least 227 species and the number of species delisted due to recovery outnumbered the number of species delisted for extinction by 14 to 7 (Scott et al., 2006). In this study, we identified all ESA listed species that are extinct or possibly extinct to quantify the number of species for which ESA protections have failed and use these figures to update the estimated number of species extinctions prevented. This is the first study in over 20 years to compile data on extinction of ESA listed species, providing an important measure of one of the world's strongest conservation laws (McMillan \& Wilcove, 1994).

\section{Methods}

To identify extinct or possibly extinct ESA listed species, we examined the status of all 1,747 (species, subspecies and distinct population segments) U.S. listed or formerly listed species, excluding species delisted based on a change in taxonomy or new information showing the original listing to have been erroneous. We determined species to be extinct or possibly extinct based on not being observed for at least ten years, the occurrence of adequate surveys of their habitat, and presence of threats, such as destruction of habitat of the last known location or presence of invasive species known to eliminate the species.

To differentiate extinct and possibly extinct species we relied on determinations by the U.S. Fish and Wildlife Service, IUCN, species experts and other sources. In most cases, these determinations were qualitative rather quantitative. Species were considered extinct if surveys since the last observation were considered sufficient to conclude the species is highly likely to no longer exist, and possibly extinct if surveys were conducted after the last observation, but were 
92 not considered sufficient to conclude that extinction is highly likely (Butchart et al., 2006; Scott 93 et al., 2008).

94

95 Source information included five-year reviews, listing rules and critical habitat designations by the U.S. Fish and Wildlife Service (for aquatic and terrestrial species) or NOAA Fisheries (for marine species), published and grey literature, personal communication with species experts, and classifications and accounts by NatureServe, IUCN and the Hawaiian Plant Extinction Prevention program. For each species, we identified year of listing, year last seen, NatureServe and IUCN ranking, taxonomic group, and U.S. Fish and Wildlife Service region. For species last seen after listing, we also searched for abundance estimates at time of listing in order to give a sense of likelihood of survival regardless of ESA protection.

Following previously developed methods, we estimated the number of species extinctions prevented by the ESA by assuming that listed threatened and endangered species have a comparable extinction risk to IUCN endangered species, which was estimated as an average of 67 percent over 100 years (Mace, 1995; Schwartz, 1999; Scott et al., 2006). We believe this estimate of extinction risk is conservative based on similarity of IUCN criteria to factors considered in ESA listings, observed low numbers for species at time of ESA listing and observed correspondence between ESA listed species and species classified as endangered or critically endangered by the IUCN (Wilcove et al., 1993; Wilcove and Master, 2005; Harris et al., 2012). Presumed extinction risk was then multiplied by the number of extant listed species and the proportion of a century in which species were protected by the ESA. Previous studies used the length of time the ESA has been in existence (1973-present) for the proportion of a 
115 century species have been protected (Schwartz, 1999; Scott et al., 2006), but because many

116 species have not been protected the entire 45 years the law has existed, we instead used the more

117 conservative average length species were protected (25 years). This corresponds to the following

118 formula:

119

120 Expected extinctions $=($ Spp. X 100 year extinction risk $X$ average proportion of a century with 121 protection).

122

123 Results

124 We identified a total of 97 ESA listed species that are extinct (23) or possibly extinct (74). Of

125 these, we found 71 extinct (19) or possibly extinct (52) species were last observed before they

126 were listed under the ESA and thus are not relevant to determining the Act's success in

127 preventing extinction (Supplemental information, Table 1). These species were last seen an

128 average of 24 years before protection was granted with a range of one to more than 80 years

129 prior.

130

131 A total of 26 species were last seen after listing, of which four are confirmed extinct and 21 are

132 possibly extinct (Supplementary information, Table 2). On average, these species were last seen

13313 years after listing with a range of 2-23 years. We were able to find an abundance estimate at

134 the time of listing for 19 of these species, ranging from one individual to more than 2,000 with

135 an average of 272. In several cases, these estimates were based on extrapolations from very few

136 sightings.

137 
138 The distribution of extinct and possibly extinct species was non-random with 64 of the 97

139 species from Hawaii and other Pacific Islands, followed by 18 from the southeast (Figure 1).

140 This was also the case for taxonomy. Forty of the 97 species were mollusks dominated by

141 Hawaiian tree snails and southeast mussels, followed by birds (18) and plants (17) (Figure 2).

143 We identified several other species that have been missing for more than 10 years, but for which

144 there has not been any effective surveys and thus classifying them as possibly extinct did not 145 seem appropriate, including two Hawaiian yellow-faced bees (Hylaeus facilis and Hylaeus

146 hilaris)(Magnacca personal communication, 2018) and Fosberg's love grass (Eragrostis

147 fosbergii)(USFWS, 2011). If indeed extinct, all three were lost prior to protection under the 148 ESA.

150 Including updated figures for number of listed species, time of protection and species 151 extinctions, we estimate the ESA has prevented the extinction of roughly 291 species in its 45

152 year history. Based on the number of confirmed extinctions following listing, we further

153 estimate that the ESA has to date prevented the extinction of more than 99 percent of species 154 under its protection. To date, a total of 39 species have been delisted for recovery compared to 155 five species that are extinct and 21 that are potentially extinct.

157 Discussion

158 The few number of listed species that have gone extinct following protection combined with an estimated 291 species for which extinction was prevented demonstrate the ESA has achieved one 160 of its core purposes - halting the loss of species. We will not attempt to catalogue them here, but 
161 numerous individual examples provide further support for this conclusion. Well known species

162 like the California condor (Gymnogyps californianus), black-footed ferret (Mustela nigripes) and

163 Hawaiian monk seal (Neomonachus schauinslandi), as well as lesser known species like the

164 yellowfin madtom (Noturus flavipinnis), are but a few of the species that likely would have been

165 lost were it not for the ESA.

166

167 The madtom is a case in point. Wrongly presumed extinct when described in1969, individual

168 madtom were found in the Powell and Copper Rivers of Tennessee and the species was protected

169 under the ESA in 1977 (USFWS, 1977). Following protection, federal and state officials worked

170 with a non-governmental organization, Conservation Fisheries Inc., to discover additional

171 populations and repatriate the species to rivers and streams in its historic range and there are now

172 populations of the yellowfin madtom in five different watersheds (USFWS, 2012a). The history

173 of the ESA is replete with similar such stories.

174

175 The distribution of extinct or possibly extinct listed species largely tracks those regions with the

176 highest rates of species endangerment, including Hawaii and the Northern Mariana Islands with

17764 of the 97 extinctions or possible extinctions, and the Southeast with 18 of the extinctions or

178 possible extinctions, mostly freshwater species. The fragility of Hawaii's endemic fauna to

179 introduced species and habitat destruction and high degree of species imperilment is well

180 recognized (e.g. Duffy \& Kraus, 2006). Similarly, the extinction and endangerment of

181 freshwater fauna in the southeast is well documented (Benz \& Collins, 1997). To avoid further

182 extinctions, these areas should be priorities for increased funding and effort. 
184 Protection under the ESA came too late for the 71 species last seen prior to listing. It's possible 185 that some of these species survived undetected following listing, but we find this unlikely for

186

187

188

190

191

192

193

194

195

196

197

198

199

200

201

202

203

204

205

206 most if not all of the species. It is very difficult to document extinction, but all of the species

were the subject of survey both before and after listing, which is described in the listing rules and subsequent status surveys. In addition, the 71 species were last seen an average of 24 years prior to listing, providing a long window for detection prior to listing. If some of these species did survive after listing it was likely at very low numbers, such that recovery would have been difficult at best.

That these 71 species were lost before protections were applied clearly highlights the need to move quickly to protect species. Indeed, Suckling et al., (2004) identified 42 species that went extinct while under consideration for protection. Since that analysis was completed, the U.S. Fish and Wildlife Service has determined five additional species did not qualify for protection because they were extinct, including the Tacoma pocket gopher (Thomomys mazama tacomensis), Tatum Cave beetle (Pseudanophthalmus parvus), Stephan's riffle beetle (Heterelmis stephani), beaverpond marstonia (Marstonia castor) and Ozark pyrg (Marstonia ozarkensis), meaning there are now 47 species that have gone extinct waiting for protection (USFWS, 2012b, 2016, 2017, 2018a).

The U.S. Fish and Wildlife Service currently faces a backlog of more than 500 species that have been determined to potentially warrant protection, but which await a decision (USFWS, 2018b). Under the ESA, decisions about protection for species are supposed to take two years, but on average it has taken the Fish and Wildlife Service 12 years (Puckett et al. 2016). Such lengthy

Peer) reviewing PDF | (2019:01:34008:1:0:NEW 9 Mar 2019) 
207 wait times are certain to result in loss of further species and run counter to the purpose of the

208 statute. This problem can be addressed by streamlining the Service's process for listing species,

209 which has become increasingly cumbersome, and by increasing funding for the listing program.

210 For every species listed, the Service's process includes review by upwards of 20 people,

211 including numerous individuals who have no specific knowledge of the species and in a number

212 of cases are political appointees. We instead recommend that the Service adopt a process similar

213 to scientific peer review, involving review by 2-3 qualified individuals.

215 The loss of 26 species after they were protected is indicative of conservation failure. This

216 failure, however, in most cases cannot be wholly attributed to the Endangered Species Act

217 because most of these species were reduced to very low numbers by the time they were

218 protected, making recovery difficult to impossible. Of the nineteen species we could find an

219 abundance estimate for at the time of listing, 13 had an estimated population fewer than 100 with

220 eight having fewer than 10 individuals. Of the six other species, two Hawaiian birds,

221 Oahu creeper (Paroreomyza maculate) and 'O'u (Psittirostra psittacea) had estimated

222 populations in the hundreds, but this was based on sightings of single individuals. Given the lack

223 of further sightings and the presence of disease carrying mosquitoes throughout their habitat,

224 these estimates were likely optimistic. The other four species, the dusky seaside sparrow

225 (Ammodramus maritimus nigrescens), Morro Bay kangaroo rat (Dipodomys heermanni

226 morroensis), pamakani (Tetramolopium capillare) and Curtis’ pearlymussel (Epioblasma

227 florentina curtisii), had populations at the time of listing ranging from 100-3,000 individuals, but

228 sufficient action was not taken to save them, making them true conservation failures. 
230 At some level, all of the 97 ESA listed species that we identified as possibly extinct or extinct are

231 conservation failures. For 42 of these species, the law itself was too late because they were last

232 seen before the ESA was passed in 1973. But for others, there may have been time and we did

233 not act quickly enough or dedicate sufficient resources to saving them. There are many

234 examples of species both in the U.S. and internationally that have been successfully recovered

235 even after dropping to very small numbers, but this can only occur with fast, effective action,

236 resources and in many cases luck. The Mauritius kestrel (Falco punctatus), for example, was

237 brought back from just two pairs (Cade \& Jones, 1993) and the Hawaiian plant extinction

238 prevention program, which focuses on saving plants with fewer than 50 individuals, has

239 rediscovered many species believed extinct, brought 177 species into cultivation, constructed

240 fences to protect species from non-native predators and reintroduced many species into the wild

241 (Wood, 2012, http://www.pepphi.org/).

242

243 The failure to provide sufficient resources for conservation of listed species, however, continues

244 to the present. As many as 27 species of Oahu tree snail (achatinella spp.) are extinct or possibly

245 extinct, yet expenditures for the species that still survive are inadequate to support minimal

246 survey and captive propagation efforts. Likewise, the Hawaiian plant extinction prevention

247 program, which has been so effective in saving species on the brink of extinction, is facing a

248 budget cut of roughly 70 percent in 2019 (http://www.pepphi.org/), which very likely could

249 mean the extinction of dozens of plants that otherwise could be saved. Overall, Greenwald et al.

250 (2016) estimate current recovery funding is roughly three percent of estimated recovery costs

251 from federal recovery plans. We can save species from extinction, but it must be more of a

252 priority for federal spending. Nevertheless, despite funding shortfalls and the tragedy of these 
253 species having gone extinct, the ESA has succeeded in preventing the extinction of the vast

254 majority of listed species and in this regard is a success.

255

256 Management Implications

257 Of the 97 species we identified as extinct or potentially extinct, only 11 have been delisted for

258 extinction. Another 11 have been recommended for delisting due to extinction. The San Marcos

259 gambusia (Gambusia georgei) could also be delisted since there is very little hope it survives.

260 For the other 74 possibly extinct species, we recommend retaining protections in the hope that

261 some will be rediscovered and because there is little cost in retaining listing.

262

263 Literature Cited

264 Benz, G.W., \& Collins D.E., (Eds.) (1997). Aquatic Fauna in Peril: The Southeastern

265 Perspective. Southeast Aquatic Research Institute Special Publication 1, Lenz Design and

266 Communications, Decatur, GA. 553 pp.

267

268 Butchart, S.H.M., Stattersfield, A.J., \& Brooks, T.M., (2006). Going or gone: defining 'Possibly

269 Extinct' species to give a truer picture of recent extinctions. Bulletin of the British

270 Ornithologists' Club, 126A, 7-24.

271

272 Cade, T.J., \& Jones, C.G., (1993). Progress in Restoration of the Mauritius Kestrel.

273 Conservation Biology, 7, 169-175. doi/abs/10.1046/j.1523-1739.1993.07010169.x

274 
275 Duffy, D. C., \& Kraus, F., (2006). Science and the Art of the Solvable in Hawai' i's Extinction

276 Crisis. Environment Hawaii, 16 (11), 3-6. Retrieved from http://www.environment-

277 hawaii.org/?p=1451

278

279 Gibbs, K.E. \& Currie D.J., (2012). Protecting Endangered Species: Do the Main Legislative

280 Tools Work? PLoS ONE, 7(5), 1-7. e35730. doi:10.1371/journal.pone.0035730

281

282 Greenwald, N., Hartl, B., Mehrhoff, L. \& Pang J., (2016). Shortchanged, funding needed to save 283 America's endangered species. Retrieved from

284 https:/www.biologicaldiversity.org/programs/biodiversity/pdfs/Shortchanged.pdf

285

286 Harris, J.B. C., Leighton Reid, J., Scheffers, BR., Wanger T. C., Sodhi, N. S., (2012).

287 Conserving imperiled species: a comparison of the IUCN Red List and U.S. Endangered Species 288 Act. Conservation Letters, 5, 64-72.

289

290 Hastings, D., Lummis C., Amodei, M., Bishop, R., Collins, D., Harris, A., ... Valadao, D., 291 (2014). Endangered Species Act Working Group Report, Findings and Recommendations.

292 February 4, 2014. Retrieved from

293 https://valadao.house.gov/uploadedfiles/esaworkinggroupreportandrecommendations.pdf

Mace, G.M., (1995). Classification of threatened species and its role in conservation planning. In 
299 Male, T. D. \& Bean, M. J., (2005). Measuring progress in US endangered species conservation.

300 Ecological Letters, 8, 986-92. doi/abs/10.1111/j.1461-0248.2005.00806.x

301

302

McMillan, M. \& Wilcove, D.S., (1994). Gone but not forgotten: why have species protected by the ESA Become Extinct? Endangered Species Update, 11(11), 5-6.

304

Schwartz, M. W., (1999). Choosing the appropriate scale of reserves for conservation. Annual 306

Review of Ecology, Evolution and Systematics, 30, 83-108.

307

doi/abs/10.1146/annurev.ecolsys.30.1.83

308

309

Scott J.M., Goble D.D., Scvancara L., \& Pidgorna A. (2006). By the numbers. In Goble, D.D.,

Scott, J.M., Davis, F.W., (Eds.), The Endangered Species Act at Thirty: Renewing the

311

Conservation Promise (pp 16-35). Island Press, Washington, DC.

312

313 Scott, J. M., Ramsey F. L., Lammertink, M., Rosenberg K. V., Rohrbaugh R., Wiens J. A., \&

Reed, J. M., (2008). When is an "extinct" species really extinct? Gauging the search efforts for

Hawaiian forest birds and the Ivory-billed Woodpecker. Avian Conservation and Ecology, 3(2),

3. http://www.ace-eco.org/vol3/iss2/art3/

Suckling, K.F., Slack, R., \& Nowicki B., (2004). Extinction and the Endangered Species Act.

319 Center for Biological Diversity. Retrieved from

320 http://www.biologicaldiversity.org/publications/papers/ExtinctAndESA.pdf 
322 Suckling, K.F., Mehrhoff, L.A., Beam, R., \& Hartl, B., (2016). A wild success, a systematic

323 review of bird recovery under the Endangered Species Act. Retrieved from

324 http://www.esasuccess.org/pdfs/WildSuccess.pdf

325

326 Taylor, M., Suckling, K., \& Rachlinski, J., (2005). The effectiveness of the Endangered Species

327 Act: a quantitative analysis. BioScience, 55, 360-367

328

329

U.S. Fish and Wildlife Service., (1977). Final Threatened Status and Critical Habitat for Five species of Southeastern Fishes. Federal Register, 42 (175), 45526-45530.

331

332

U.S. Fish and Wildlife Service., (1990). Final Rule to Delist the Dusky Seaside Sparrow and

Remove its Critical Habitat Designation. Federal Register, 55, (239), 51112-51114.

334

335

U.S. Fish and Wildlife Service, (2011). Eragrostis fosbergii (Fosberg's love grass) 5-Year

Review Summary and Evaluation. Retrieved from

https://ecos.fws.gov/docs/five_year_review/doc3814.pdf

U.S. Fish and Wildlife Service, (2012a). Yellowfin Madtom (noturus flavipinnis), Smoky

Madtom (Noturus baileyi) 5-Year Review Summary and Evaluation. Retrieved from

https://ecos.fws.gov/docs/five_year_review/doc4146.pdf 
343 U.S. Fish and Wildlife Service, (2012b). Listing Four Subspecies of Mazama Pocket Gopher and

344 Designation of Critical Habitat, Proposed Rule. Federal Register, 77, 73769-73825.

345

346 U.S. Fish and Wildlife Service, (2016). Endangered and threatened wildlife and plants; 12-

347 Month findings on petitions to list 10 species as endangered or threatened species. Federal

348 Register, 81, 69425-69422.

349

350

U.S. Fish and Wildlife Service, (2017). Endangered and threatened wildlife and plants; 12-month

351 findings on petitions to list a species and remove a species from the federal lists of endangered

352 and threatened wildlife and plants. Federal Register, 82, 61725-61727.

353

354

U.S. Fish and Wildlife Service, (2018a). Endangered and threatened wildlife and plants; 12-

355

month findings on petitions to list 13 species as endangered or threatened species. Federal

356

Register, 83, 65127-65134.

357

358

U.S. Fish and Wildlife Service, (2018b). Listing and Critical Habitat Workplan. Retrieved from 359

https://www.fws.gov/endangered/what-we-do/listing-workplan.html.

360

361 Wilcove, D.S, McMillan, M., \& Winston, K.C., (1993). What exactly is an endangered species?

362 An analysis of the U.S. endangered species list: 1985-1991. Conservation Biology, 7(1), 87-93.

363

364 Wilcove, D.S. \& Master, L.L., (2005). How many endangered species are there in the United

365 States? Frontiers in Ecology and the Environment, 3(8), 414-420 
367 Wood, K.R., (2012). Possible Extinctions, Rediscoveries, and New Plant Records within the 368 Hawaiian Islands, Records of the Hawaii Biological Survey for 2011. In Evenhuis, N.L., \& 369 Eldredge, L.G., (Eds.). Bishop Museum Occasional Papers 113, 91-102.

370 
Figure 1 (on next page)

Extinction and taxonomic group

Figure 1. Extinct or possibly extinct listed species by taxonomic group. 


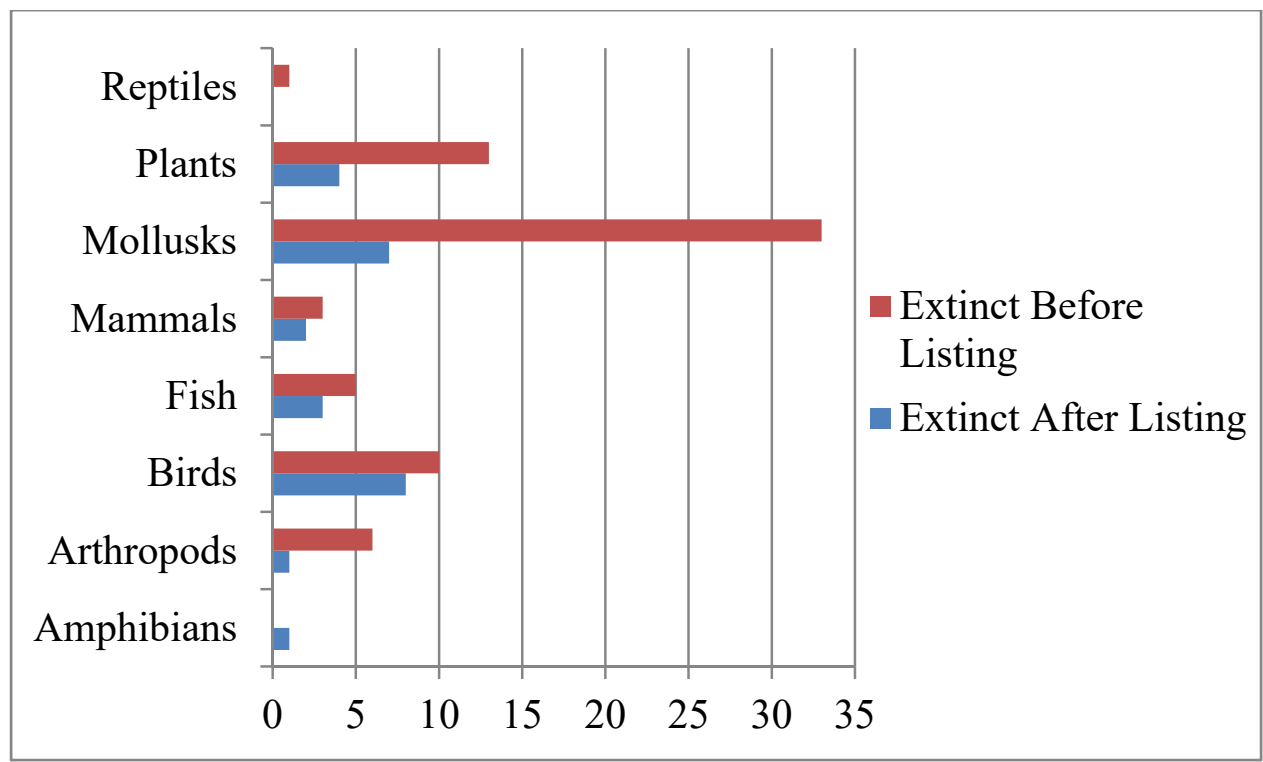

Figure 1. Extinct or possibly extinct listed species by taxonomic group. 
Figure 2 (on next page)

Extinctions by region

Extinct or possibly extinct listed species by U.S. Fish and Wildlife Service Region. 


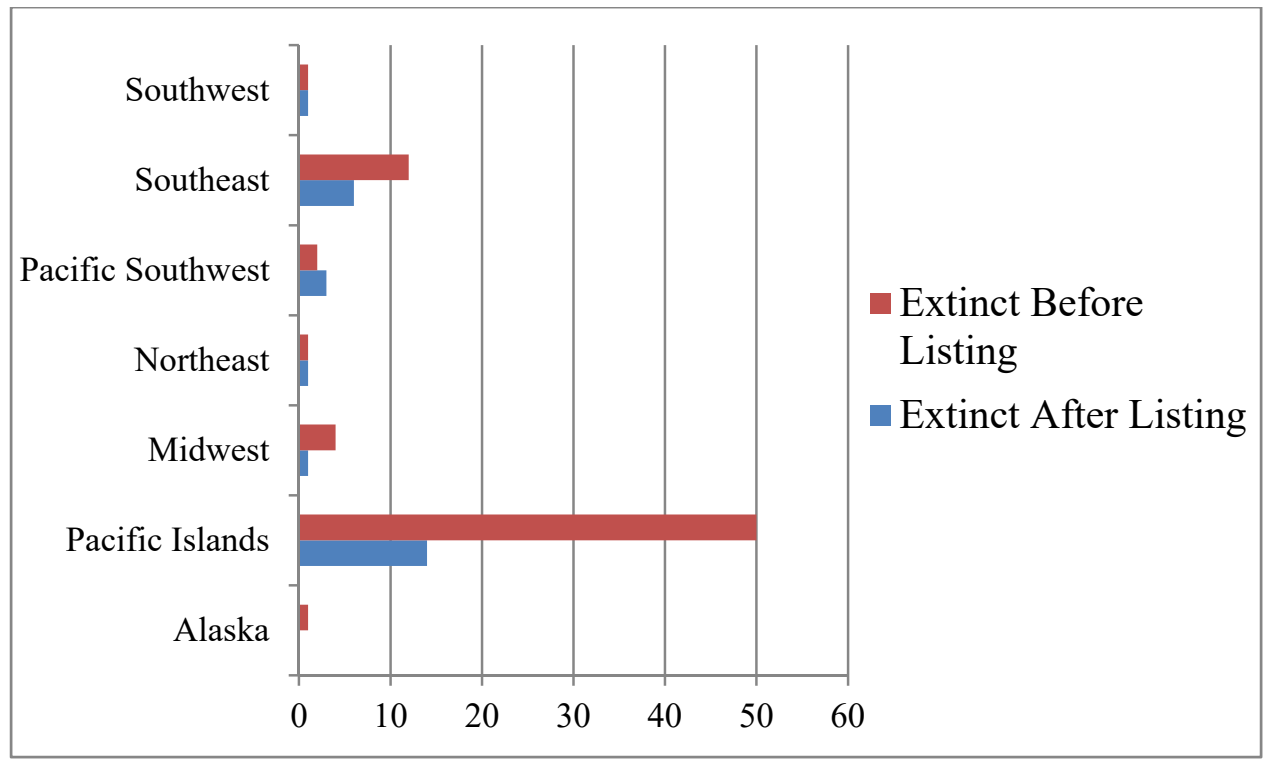

Figure 2. Extinct or possibly extinct listed species by U.S. Fish and Wildlife Service Region. \# 